\title{
Representações de morte e desvio em narrativas jornalísticas da Amazônia urbana
}

\author{
Sergio do Espirito Santo Ferreira Junior \& Alda Cristina Costa \\ Universidade Federal do Pará \\ E-mail: esferreira.sergio@gmail.com/aldacristinacosta@gmail.com
}

\section{RESUMO}

O objetivo deste artigo é analisar como as narrativas jornalísticas produzidas na Amazônia Paraense apresentam as mortes por violência urbana, ancorando-as às representações sociais do bem e do mal, definindo e participando da construção social do fenômeno da violência e da rotulação de desviantes. As narrativas estão inseridas na rotina cotidiana de repercussões em um ambiente sociossimbólico, cujas representações sociais são alimento para as narrativas das mídias jornalísticas e são por elas alimentadas. Pensamos como a comunicação midiática rearranja o fenômeno, na produção de experiência social em uma cotidianidade.
Analisamos as narrativas dos principais jornais impressos da região, Amazônia, Diário do Pará e O Liberal, cujo modus narrandi é permeado pela reiteração dualista das mortes por violência urbana, apresentadas como a morte inesperada dos bons e a morte naturalizada dos maus. Pensamos as representações sociais a partir do pensamento de Moscovici e Jovchelovitch, como sistema interpretativo formado por formas de conhecimento socialmente partilhadas, que ordenam e governam as condutas dos indivíduos, face aos objetos sociais da vida cotidiana, constituindo-a, por meio de processos de ancoragem e objetivação.

Palavras-chave: representações sociais;narrativas jornalísticas; morte; desvio; violência; Amazônia Paraense.

Data de submissão: 11-05-2016. Data de aprovação: 23-10-2016.

A Revista Estudos em Comunicação é financiada por Fundos FEDER através do Programa Operacional Factores de Competitividade - COMPETE e por Fundos Nacionais através da FCT - Fundação para a Ciência e a Tecnologia no âmbito do projeto Comunicação, Filosofia e Humanidades (LabCom.IFP) UID/CCI/00661/2013.

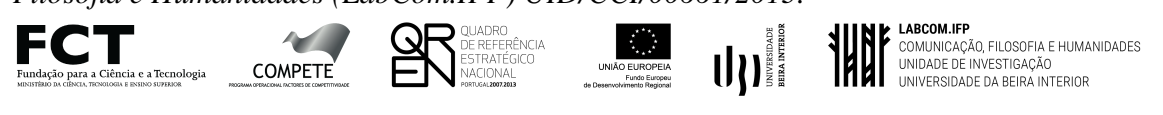




\begin{abstract}
The purpose of this article is to analyze how the journalistic narratives produced in Pará Amazon present deaths from urban violence, anchoring them to the social representations of good and evil, while defining and participating in the social construction of the phenomenon of violence and labeling deviants. The narratives are embedded in everyday routine repercussions in a socio-symbolic environment, whose social representations are food for the narratives of news media and are fed by them. We think how media communication rearranges the phenomenon, in the production of social expe-

major newspapers in the region are analyzed. They are Amazônia, Diário do Pará e O Liberal whose modus narrandi is permeated by dualistic reiteration of deaths from urban violence, presented as the good of unexpected death and naturalized death of the wicked. The social representations from the thought of Moscovici and Jovchelovitch as interpretive system formed by forms of knowledge socially shared, that order and govern the conduct of individuals, given the social objects of everyday life, making it through processes anchoring and objectification are used throughout this article..
\end{abstract} rience in a daily life. The narratives of

Keywords: social representations; journalistic narratives; death; deviance; violence; Amazon from Pará.

\title{
INTRODUÇÃO
}

$\mathrm{N}^{\circ}$

O Brasil, a violência começa a ser pauta de discussão, nos idos de 1960, quando o cineasta Glauber Rocha começa a trabalhar em seus filmes a temática do cinema revolucionário, do auge do "populismo engajado" e também do golpe militar. A violência entra em cena no debate nacional, quando já não se podia negar o conflito presente nas diversas esferas da sociedade, as várias formas de exclusão social, os preconceitos em relação a diferentes minorias e mesmo algumas evidências da tensão entre classes sociais no país. A partir disso, os brasileiros começam a ter ideia do Brasil e da violência, que hoje, assume a totalidade das discussões tanto no dia-a-dia social quanto no imaginário coletivo. Em 1980, com a intensificação do processo de redemocratização, a discussão em torno do fenômeno da violência ganha um grande espaço, ocupando boa parte dos noticiários da mídia, "pulando" das páginas 
policiais para os cadernos mais importantes e para os telejornais e programas diários televisivos.

A onipresença do crime e da violência na mídia brasileira tem estimulado uma série de debates a respeito do quanto essa mídia pode alimentar ansiedades, formar atitudes, definir valores ou incentivar comportamentos diversos no público, já que é nessa intrincada relação que os indivíduos percebem as representações construídas pelas narrativas midiáticas textuais, visuais, orais ou imagéticas.

Considerando o cenário de complexificação da problemática urbana e da questão social, as mídias jornalísticas têm procurado dar respostas - espetacularizadas ou não - à população, que se queda atônita diante da dificuldade de compreensão das bases societárias geradoras da incivilidade e violência crescentes (Telles, 2010). A população brasileira acompanhou o nascimento de narrativas midiáticas, jornalísticas ou não, que passaram a explorar o fenômeno da violência. Não seria ruim se esse crescimento levasse a sociedade a refletir sobre o problema social. Percebe-se, no entanto, que as narrativas, quase sempre, ficam no campo da encenação do real e do reforço simbólico da segregação social. Ao discutir esse problema social é preciso contextualizá-lo num mundo social permeado de contrastes, mas além dos valores em oposição, tais como riqueza e pobreza; coletivo e individual; inclusão e exclusão; bem e mal; modernidade e atraso; ter e ser.

Violência nas ruas, nas escolas, nos estádios, nos lares, no trânsito, na mídia, entre outros lugares, criam um clima de instabilidade e de insegurança constantes. Violência que passa a povoar o imaginário das pessoas, mudando hábitos e transformando os espaços de convivência. Diante disso, realizamse esforços de compreender a relação entre violência-mídia-sociedade. Nesse processo, a mídia participa ativamente da construção do imaginário e experiência sociais, no interior dos quais os indivíduos percebem-se em relação a si mesmos e, sobretudo, em relação aos outros. Dessa percepção vem a visualização do sujeito como parte de uma coletividade e de outros sujeitos como marginais a ela.

A mídia entra numa disputa direta ou indireta de poder com o Estado. É ela que "vê", "ouve" e "fala" pelas e para as pessoas, gerando esvaziamento, conforme argumenta Marcondes Filho (2008), entre população, de um lado, e Estado e instituições político-sociais, do outro; de modo que os meios de comunicação "tomaram" seu lugar. A comunicação midiática "passa a ocu- 
par" simbolicamente o lugar das instituições, fato esse que provoca distorções significativas: a população em vez de se dirigir à justiça para garantir seus direitos, à polícia para obter mais segurança, às escolas e universidades para aprender e melhorar sua formação, recorre à mídia, para "defender" e "proteger" seus direitos, por meio da visibilização.

Ocorreram avanços na produção de narrativas sobre a violência no Brasil na última década, por meio da reformulação das linguagens e modelos utilizados para tratar da temática, da extinção de parte dos cadernos de polícia ou, pelo menos, de um afastamento da exposição sensacional e espetacular sobre a violência na mídia de alguns estados brasileiros (Ramos \& Paiva, 2007). No entanto, não se podem ignorar os usos da violência urbana feitos em âmbitos local e regional mesmo hoje, já que a relevância da cobertura sobre segurança pública é enviesada. Há a consolidação de modos de narrar espetaculares e ampla negação do debate sobre segurança pública e sobre a violência como problema social complexo; deslocamentos se operam pela espetacularização das violências espetaculares, em que as mortes por homicídios ou outras motivações representam ainda uma das chaves da narrativa e principal alimento noticioso.

Há no Brasil, portanto, uma lógica industrial da violência na mídia, cujos usos priorizam a produção de narrativas textuais e imagéticas sobre as mortes, a face mais evidente das representações da violência. As narrativas jornalísticas inserem-se em um processo de produção e difusão de representações, nas quais se inscrevem deslocamentos e interpretações sobre violência e realidade social. Consideramo-las inseridas em um processo de repercussões em um ambiente sociossimbólico, do ponto de vista da difusão de representações que virtualmente se relacionam a representações além e aquém das narrativas midiáticas, e que se rearranjam na produção de experiência social em uma cotidianidade.

Institucionalizou-se na mídia do estado brasileiro do Pará, que configura a Amazônia Paraense ${ }^{1}$, um modus narrandi em que a violência urbana e segurança pública são dadas a ver como ocorrências de criminalidade e seus en-

1. A Amazônia Paraense é um termo usado para identificar o estado brasileiro do Pará, considerando a sua inserção no ambiente heterogêneo da Amazônia. Do ponto de vista das categorias administrativas, o estado do Pará é parte da Amazônia Oriental, sub-região da Amazônia Legal, que é composta pelos estados do Amapá, Maranhão, Pará e Tocantins. O território que compreende toda a Amazônia Legal é formado pelos estados do Acre, Amapá, Amazonas, 
volvidos. A linguagem pode apresentar gradações em suas linhas editoriais, que vão de um tratamento menos espetacular e supostamente mais objetivo até o mais banalizado, agressivo e chulo. No Pará, no entanto, todas as mídias jornalísticas apresentam em suas narrativas um "painel da violência diária", construídos como se fossem relatos policiais sobre Belém, capital do estado, a sua região metropolitana e sobre o interior do estado. Elaboram um panorama interpretativo que pontua determinados elementos da realidade social violenta, ancora-os a territórios, apresenta seus agentes e pacientes, em um processo de reiteração e autorreferência diárias e constantes.

A partir do mapeamento dos impressos da região, analisamos neste trabalho como o processo de narrativização da morte por violência urbana ancora a violência a representações do bem e do mal, objetivando-as. Observamos que as narrativas construídas sobre as mortes decorrentes da violência urbana evidenciam as ocorrências violentas concentradas na periferia da cidade, mobilizando a percepção desses espaços urbanos como locais cada vez mais perigosos, dominados pelo crime e tráfico, ou mesmo personalizando-os, relacionando a violência diretamente a indivíduos e grupos, que seriam seus causadores. Desse modo, essas narrativas participam de uma construção social do desvio, da definição do mal e dos maus na sociedade, que habitam espaços marcados por sociabilidades violentas, assim como de seus contrários.

Partimos de uma perspectiva que compreende as narrativas midiáticas implicadas em repercussões sociossimbólicas (Ferreira Junior \& Costa, 2016) ou naquilo que Correia (2009) aponta como processos sociocognitivos em torno do jornalismo e da sua produção discursiva. Em nossas análises, realizamos uma aproximação teórico-metodológica entre representações sociais (Jovchelovitch, 2000, 2008, Moscovici, 2011) e narrativas jornalísticas (Motta, 2013), para compreender a difusão de conhecimentos sobre a violência urbana. Pensamos, assim, como as mortes decorrentes da violência urbana emergem nesse processo de narrativização e difusão de representações. Discussões adjacentes acrescentam-se a essa, à medida que, para compreender as representações sociais, são apresentados "outros" sociais, identificados como desviantes ou outsiders (Cohen, 2011; Becker, 2008), que não se alinham a ideais normati-

Pará, Rondônia, Roraima, Tocantins, Mato Grosso e parte do Maranhão, sendo área demarcado pela Superintendência do Desenvolvimento da Amazônia (SUDAM), em 1966. (Brasil, 2012). 
vos, que não fazem parte da ordem social, porém são vítimas dessa violência na Amazônia Paraense.

A perspectiva que pretendemos dispensar às narrativas sobre a morte na mídia impressa da Amazônia Paraense é resultado de reflexões realizadas no âmbito do projeto de Pesquisa Mídia e Violência: as narrativas midiáticas na Amazônia Paraense ${ }^{2}$. Selecionamos 12 edições entre 42 jornais retirados do acervo do projeto, que continham as maiores quantidades de fotografias com marcas de violência. Os jornais que constituem o corpus do projeto e aparecem neste artigo são: O Liberal e Diário do Pará, do primeiro e do segundo semestre de 2012; e Amazônia, do primeiro e do segundo semestre de 2013.

\section{AS REPRESENTAÇÕES COMO AMBIENTE SOCIOSSIMBÓLICO}

Ao falar da violência urbana no Brasil, referimo-nos a um fenômeno contextualmente localizado, condicionado pela formação da sociedade brasileira e suas dinâmicas. $\mathrm{O}$ atual ambiente sociossimbólico em que se delineia uma cultura do medo da violência, que ordena praticas cotidianas, movimenta uma economia do medo, é formado por um processo complexo de circulação de referências e interpretações sobre o ambiente urbano, em que as representações se tornam uma espécie de mapa para orientar os indivíduos da sociedade. Um mapa, poderíamos inferir, que se sobrepõe ao território, como afirma Baudrillard (1991), em um processo de simulação na qual já não se consegue definir o real, na qual a sociedade é projetada por meio de imagens que se perfazem na ubiquidade de simulacros. Segundo Baudrillard, os "simuladores atuais" engendram simulacros que compõe uma espécie de realidade que já não é claramente distinguível, pois que toda a vida e a sociedade passam hoje pelo seu filtro. Em uma relação entre as "ordens do real" e "ordens do hiper-real", o simulacro é da ordem do hiper-real, uma vez que se trata de uma realidade que se sobrepõe ao real, por meio da superabundância das imagens, marcadamente, das imagens midiáticas.

2. O Projeto de pesquisa Mídia e Violência: as narrativas midiáticas na Amazônia Paraense foi realizado em parceria entre Universidade Federal do Pará (UFPA) e Conselho Nacional de Desenvolvimento Científico e Tecnológico (CNPq), durante a qual foi analisado um ano de edições dos três grandes jornais impressos paraenses que circulam na região: Diário do Pará, O Liberal e Amazônia. 
Podemos, no entanto, ir além de pensar do ponto de vista do simulacro, de uma realidade imagética e simulada, para pensar as mídias jornalísticas e a narrativização da violência urbana, considerando o caráter refratário dessas narrativas, os deslocamentos que instauram, mas também os processos de forjamento de subjetividade social complexos nos quais se inserem. Buscamos pensar o lugar da comunicação midiática na construção de narrativas, que organizam simbolicamente a realidade cotidiana e que se espraiam no tecido social, como partícipes da configuração do ambiente sociossimbólico relacionado à violência. Falamos, assim, não de representações que têm efeitos diretos e totalizantes nos usuários nem de simulacros que sozinhos configuram toda a realidade, mas de narrativas que participam de uma organização simbólica da vida social e têm relevância contemporânea, ao fazer emergir a violência, em um contexto do qual ela é um elemento percebido e representado cotidianamente.

Aquilo que chamamos de ambiente sociossimbólico trata-se de um ambiente de pensamento formado por representações sociais, conhecimentos da vida cotidiana e de outros espaços da vida social, possuidoras de uma dimensão social e simbólica (Jovchelovitch, 2008; Moscovici, 2011). O conceito de representações sociais é elaborado por Moscovici, que as entende como conceito de uma teoria e também como o fenômeno das formas de conhecimento da sociedade. Para ele, essas representações são produzidas constantemente pela interação e pela comunicação, transformando-se em senso comum, parte de um mundo comum do cotidiano no qual habitamos. Elas circulam nas mídias, nas interações face-a-face, e são produzidas por pessoas inseridas em circunstâncias especificas. Moscovici pensa o lugar da comunicação, do ponto de vista relacional, para demarcar os processos constituidores dessas representações, considerando mesmo a comunicação midiática, cujo papel na produção e difusão de representações sociais outros autores têm reconhecido (Jodelet, 2001; Jovchelovitch, 2000; Porto, 2014).

Assim, as representações, diz Moscovici, orientam-nos frente àquilo a que temos que responder e àquilo que é visível, relacionando aparência e realidade, definindo tal realidade. Forjam-se e se inserem em um ambiente social e cultural, uma atmosfera, pois se constituem em uma espécie de mundo da realidade, não são produzidas por um indivíduo, mas são "partilhadas por tantos, penetram influenciam a mente de cada um, elas não são pensadas por eles; melhor, para sermos mais precisos, elas são re-pensadas, re-citadas e 
re-apresentadas" (Moscovici, 2011, p. 37), operando simbolicamente na prescrição das percepções, de modo a constituir um mundo real e concreto. Para ele, na sociedade contemporânea, agentes como os meios de comunicação de massa respondem à necessidade de re-construir um senso comum, que é o substrato de imagens e sentidos das coletividades. Nesse processo, na relação entre a sociedade e seus mundos, os indivíduos transformam as representações em um fenômeno à parte, mas com estrita relação com aquilo que elas identificam, descrevem e objetivam. Desse modo, esse ambiente, essa realidade partilhada e relacionada à interação entre pessoas, corporifica ideias em experiências dentro de uma sociedade pensante, na qual

Pessoas e grupos criam representações no decurso da comunicação e da cooperação. Representações, obviamente, não são criadas por um indivíduo isoladamente. Uma vez criadas, contudo, elas adquirem vida própria, circulam, se encontram, se atraem e se repelem e dão a oportunidade ao nascimento de novas representações, enquanto velhas representações morrem. Como consequência disso, para se compreender e explicar uma representação, é necessário começar com aquela, ou aquelas, das quais ela nasceu. [...] sendo compartilhada por todos e reforçada pela tradição, ela constitui uma realidade sui generis. Quanto mais sua origem é esquecida e sua natureza convencional ignorada, mais fossilizada ela se torna. O que é gradualmente ideal, gradualmente torna-se materializado. Cessa de ser efêmero, mutável e mortal e torna-se, em vez disso, duradouro, permanente, quase imortal. Ao criar representações, nós somos como o artista, que se inclina diante da estátua que ele esculpiu e a adora como se fosse um deus (Moscovici, 2011, p. 41, grifo do autor).

O ambiente do pensamento é, portanto, o mundo das representações sociais, por elas constantemente formado e reformulado. Essas representações integram um sistema cognitivo formado por formas de conhecimento socialmente partilhadas, que ordenam e governam as condutas dos indivíduos, face aos objetos sociais. As representações sociais emergem como fenômeno no processo de definição do conhecimento e dos saberes sobre a vida social. Jovchelovitch, a respeito delas, afirma que as representações não são uma cópia do mundo, elaborada por um único indivíduo, mas "uma forma dialó- 
gica gerada pelas inter-relações eu/outro/objeto-mundo" (2008, p. 28). Para ela, os processos representacionais, em sua dimensão sociossimbólica, formam e expressam mundos subjetivos, intersubjetivos e objetivos, que podem emergir de diferentes esferas, com múltiplas dimensões. Como problema de conhecimento, essas representações são saber sobre objetos sociais específicos, transformados pela comunicação e pela interação social. Esses saberes são produzidos na e pela vida cotidiana, podendo ser definidos como um conhecimento que fala sobre história, tradições, identidades e modos de estar no mundo de um grupo. Esse conhecimento não é limitado, é partilhado por comunidades que possuem sistemas representacionais. Nessa perspectiva, o social é um elemento relevante no condicionamento das origens desse saber, em uma dinâmica em que representação e contexto se imbricam, e se constituem mutuamente. "É o contexto social que propicia o ponto de partida-chave para a compreensão de formas especificas de comunicação, de inter-relações, de práticas que formam e transformam os processos psicossociais que configuram as representações sociais". (Jovchelovitch, 2008, p. 92).

Essa mesma questão sobre o conhecimento nos guia ao pensarmos as narrativas das mídias jornalísticas e a sua relação com o fenômeno da violência. Não é uma nova perspectiva a de que o jornalismo se constitui como uma atividade produtora de formas de conhecimento sobre a realidade social. Para Tuchman, as notícias não podem ser definidas nos termos de um espelho da sociedade, mas no processo de uma rotinização dos acontecimentos pelo jornalismo, por meio do qual essas notícias constituem a realidade como "como fenômeno social partilhado, dado que no processo de descrição dos acontecimentos, as notícias definem e moldam o acontecimento" (Tuchman, 2002, p. 92). Essa conceptualização do jornalismo a partir do fornecimento de conhecimento social também é encontrada em Correia (2009), que defende uma abordagem sociocognitiva sobre o jornalismo, compreendendo a necessidade de pensar a definição dessa realidade e seus acontecimentos, e mesmo a discursividade dessa atividade.

Correia delineia um quadro que permite compreender como o jornalismo se constitui como uma atividade produtora de conhecimento cotidiano sobre o mundo social. Refere-se, pois, a um processo de objetivação da experiência, em que o jornalismo atribui significados aos acontecimentos, comportando também uma dimensão discursiva. Para o autor, a origem dos conhecimentos é fundamentalmente social e se dá pela experiência cotidiana, que produz esse 
acervo de conhecimentos socialmente disponíveis que se manifestam em um "conjunto de saberes, informações e operações do dia-a-dia de que o agente dispõe para interagir com o mundo, interpretá-lo e adaptar-se a ele" (Correia, 2009, p. 57). Assim como falamos da representação social nos termos de um saber cotidiano, organizador de condutas e socialmente partilhado, Correia afirma que

O conhecimento sociocultural pode ser definido como o conjunto de todas aquelas crenças que são partilhadas virtualmente por todos os membros competentes de uma dada cultura e que são definidos como verdade pelos membros que partilham os mesmos critérios [...] o conhecimento sociocultural é um grande conhecimento próprio do mundo da vida quotidiana, na medida em que se recusa a se submeter-se à crítica do próprio conhecimento, aceitando, antes, as evidências socialmente partilhadas

Desse modo, percebemos o jornalismo como um meio que se apropria, difunde e faz circularem representações em torno do fenômeno da violência urbana, que delineiam um campo de investigação que vai além da ocorrência factual da violência urbana, com a qual se ocupam as instituições do Estado, do ponto de vista organizacional, e âmbitos como Direito e outras Ciências Sociais, do ponto de vista científico. Não negamos haver, no entanto, mesmo nessa factualidade, o problema das representações, pelo contrário, reconhecemo-lo nela. Por isso mesmo, parte da investigação relacionada às representações sociais precisa compreender as suas condições de emergência, as especificidades do objeto social e do ambiente sociossimbólico que se estrutura em torno desse objeto, assim como as rotinas organizacionais cujo trabalho instaura o trânsito das representações.

\section{VIOLÊNCIA, MEDO E DESVIO NA "FOBÓPOLE"}

As narrativas jornalísticas sobre violência são elaboradas em relação a um ambiente sociossimbólico do medo da violência urbana. É nesse ambiente de representações que se constrói a fobópole (Souza, 2008), fenômeno em que a experiência da cidade no Brasil se constitui como uma experiência do medo, que emerge de um contexto no qual a violência urbana se faz sentir além da ocorrência localizada, em que todos os espaços urbanos caracterizam 
uma "cidade dominada pelo medo da criminalidade violenta", que se manifesta em práticas diversas, como as reações de autoproteção da classe média e das elites, a produção de narrativas midiáticas e a militarização do cotidiano, sobretudo, em relação aos habitantes das áreas periféricas, espaços que, no imaginário da classe média e da elite, são os causadores da violência, devem ser contidos, vigiados e controlados.

O sentimento de medo generalizado caracteriza a relação com a cidade. Nessa dinâmica há "uma situação de violência difusa, ações e reações de ressentimento, ódio e violência de cidadão contra cidadão em uma multiplicidade de situações no interior de uma cidade e de um país" (Souza, 2008, p. 36), que organiza a fobópole, a "cidade em que grande parte de seus habitantes, presumivelmente, padece de estresse crônico [...] por causa da violência, do medo da violência e da sensação de insegurança" (Souza, 2008, p. 40).

É nessa fobópole brasileira, marcada pelo medo, que habitamos. Essa fobópole é o espaço social que se desenvolveu face à emergência da violência urbana. Conquanto a violência urbana seja parte visível desse contexto ${ }^{3}$, a sua transposição para o ambiente sociossimbólico comporta distorções e exageros. Podemos falar, a partir de perspectivas similares, de uma cultura do medo (Glassner, 2003) ou mesmo de pânicos morais (Cohen, 2011). Em Glassner, a cultura do medo é caracterizada por um alarmismo em torno de matérias sociais como crime e violência, gerando um pânico que dialoga com ansiedades culturais, com conservadorismo, com o processo de produção de "outros" sociais, no qual as mídias jornalísticas e seus produtos são relativamente bemsucedidos em construir um cenário do medo que deve ser alimentado. Em Cohen, o pânico moral é um processo de construção social do desvio e da reação exacerbada face a eles. De acordo com Cohen, inferir sobre o pânico moral não significa que se refere a fenômenos que não ocorreram ou que as reações são baseadas em histeria, fantasia ou ilusão. Antes, o que se opera são

3. A violência urbana no Brasil é parte indissociável do contexto democrático brasileiro. De acordo com Cerqueira (2014), na década de 1980, mesmo antes do término da ditadura militar (1964-1985), a recessão econômica, o crescimento das populações urbanas, a manutenção dos padrões de concentração de renda e o aumento da desigualdade social, fez com que houvesse um aumento nos "incentivos a favor das atividades criminosas" (2014, p. 42). O quadro se manteve na década de 1990, só apresentando alterações significativas a partir do início do século XXI, com a contenção da violência letal, e o reforço nas políticas públicas de segurança no âmbito do Governo Federal. 
exageros e distorções em torno da significação ou extensão dos acontecimentos.

Uma condição, episódio, pessoa ou grupo de pessoas emerge para se tornar uma ameaça aos valores e interesses sociais; sua natureza é apresentada de modo estilizado e estereotípico pelos meios de comunicação de massa; as barricadas morais são ocupadas por editores, políticos e outras pessoas com direito de pensamento; especialistas socialmente creditados expõe seus diagnósticos e soluções; [...] às vezes o objeto do pânico é bastante novo e, em outras, é algo que já existe, mas repentinamente aparece sob holofotes. Às vezes o pânico passa e é esquecido, exceto no folclore e na memória coletiva. Em outras, ele tem repercussões mais sérias e duradouras, podendo produzir mudanças, como em políticas sociais, ou mesmo no modo como a sociedade concebe a si mesma (Cohen, 2011, p. 1, tradução nossa).

A si mesma e aos outros. Isso insere sobremaneira o problema do desvio, à medida que por meio desse processo passa-se às encarnações estereotípicas da violência e aos comportamentos ou tipos sociais a ela relacionados. $\mathrm{O}$ desvio, como o concebe Cohen (2011), é construído como forma de exercício do controle social, à medida que ele é construído socialmente sempre definido por alguém, em relação a algo, nunca sendo um modo de ser a priori. Ele perpassa a dimensão, portanto, de algo definido como um problema social, em condições de acordo com as quais os comportamentos dos indivíduos são descritos como disfuncionais, ameaçadores ou perigosos. Becker (2008) estabelece o desvio a partir do outsider, resultado de um processo de rotulação pelos grupos sociais por meio da "criação de regras cuja infração constitui desvio" (2008, p. 22). Desse modo, o ser desviante não é qualidade dele ou de seu ato, mas é consequência da aplicação de sanções ao indivíduo considerado infrator e da maneira como o grupo reage a ele.

Esse processo de identificação e definição dos desviantes, nas próprias mídias jornalísticas do Brasil, define-se por narrativas que, segundo Matheus (2011), apresentam a morte, marcadamente, morte de um outro, negro ou pobre, como instância objetiva do medo do desconhecido, da incivilidade, da ameaça à sociedade. Em um grau maior de especificação e identificação, o outro é comumente representado pelos traficantes e usuários de drogas, que 
encarnam a culpa; cuja morte ou prisão não representa uma ruptura, mas uma resolução ao problema da ordem, instaurado pela existência de tais desviantes. Desse modo, a narrativa midiática constrói o medo na esfera urbana por meio de uma articulação entre medos da violência e narrativização desse fenômeno, realimentando-o.

\section{AS MORTES VIOLENTAS NA CULTURA MIDIÁTICA DO ESPETÁCULO}

Desse modo, pensar as narrativas jornalísticas e a sua relação com os fenômenos da violência urbana conduz-nos a pensar os elementos que as constituem, que as condicionam. Ao pensar as representações sociais, como o fizemos acima, como formas de conhecimento partilhadas, que definem nossas relações com os objetos sociais, organizadoras de condutas e de práticas, demarcamos implicitamente duas dimensões que devem levadas em consideração quando estudamos as narrativas de violência: a do fenômeno social e do ambiente sociossimbólico em relação à violência na sociedade brasileira. "Nesse sentido, o problema é de como representações sociais e a vida pública se relacionam, ou seja, como a vida pública dá origem a representações que se tomam, elas mesmas, constitutivas do objeto que originalmente as formou" (Jovchelovitch, 2000, p. 32).

Os três maiores impressos paraenses, Amazônia, Diário e O Liberal ${ }^{4}$, estão inseridos em uma cultura do espetáculo, mas também são produzidos em mercado de comunicação marcado pela concentração midiática, por uma guerra político-empresarial em torno dos grupos proprietários dessas empresas de mídia, no qual as versões sobre a realidade social da região e seus problemas sociais estão condicionados aos tensionamentos entre público e

4. O Amazônia e O Liberal são jornais das Organizações Rômulo Maiorana (ORM), da família Maiorana. O primeiro tem formato berliner, com ênfase em notícias sobre programação televisiva, esportes e violência; foi criado em 2000, para fazer frente ao Diário do Pará, com linha editorial similar. O Liberal foi criado em 1966, pela aquisição de maquinário gráfico de um antigo jornal e se alinhou ao regime militar; ele tem formato broadsheet, e se apresenta como um jornal para a elite, ainda que tenha a editoria de polícia, com notícias de violência. Já o Diário do Pará, pertence à Rede Brasil Amazônia de Comunicação (RBA), da família Barbalho, e foi fundado em 1982, para apoiar a candidatura de Jader Barbalho, sobrinho do dono do jornal, ao governo do estado do Pará. Em 2003, o jornal passa a publicar notícias de violência urbana em um caderno em formato tabloid, destacável do resto do impresso, em formato broadsheet. 
privado, expresso nas rotinas narrativas do jornalismo (Castro, 2012, Costa, 2011, Veloso, 2014). É nesse cenário que nos questionamos sobre o problema da violência na mídia, as representações de que se alimenta e que faz circular. Esse fenômeno midiático e representacional é particularmente presente no que Costa (2011) identifica como "modelos midiáticos do espetáculo", cujos aspectos se aplicam aos muitos níveis de rotinas narrativas da mídia brasileira, mas também são fenômeno predominante na mídia da Amazônia Paraense.

O que se percebe é que a violência tornou-se fato comum, notícia corriqueira, com o interesse de comover, mexer com os sentimentos, não importando de que forma está sendo apresentada a informação. O importante é padronizar comportamentos, tratar as notícias como "produtos" sujeitos à "lei de mercado", recorrendo dessa forma ao sensacionalismo e à violência, glamourizando o crime e criando estratégias de sedução para os telespectadores [e leitores], aproximando e eliminando as fronteiras entre jornalismo, entretenimento e publicidade. Como mercadoria, a violência passa a ser consumida, integrando o processo de sua produção, ainda que como representação. Os fatos são tirados de seu contexto concreto e transmitidos como se fossem eventos fragmentados (Costa, 2011, p. 180).

Em relação à violência, esses modelos se caracterizam por fronteiras borradas, por dinâmicas de infoentretenimento, em que o caráter de espetáculo, de imagem-mercadoria, é dominante e uma das únicas fontes de informação sobre o fenômeno social. São as imagens e narrativas midiáticas que inserem a violência em parte da vida pública da Amazônia Paraense, rotulando os espaços, transcendendo o aqui e agora dos indivíduos, participando da formação de uma experiência mediada ampla sobre a violência, mas calcada nas representações e nos deslocamentos inscritos nos artefatos midiáticos.

O modus narrandi dos modelos midiáticos do espetáculo reproduz lógicas de relatos policiais, privilegiando as Polícias Civil e Militar como como fonte principal, apresentado os casos e os crimes, etapas da ação policial, expondo os acusados, citando as vítimas, apontando a origem da violência nas regiões periféricas e mostrando as evidências da violência cotidiana. Tais narrativas identificam, reiteram e reapresentam agentes, pacientes e espaços de violência urbana. 
Podemos dizer que as linhas editoriais do Diário do Pará, de O Liberal e do Amazônia definem a maneira como abordam a violência, os estilos narrativos, os ângulos da fotografia de cadáveres, a maior ou menor agressividade nas manchetes, entre outros aspectos presentes no tratamento da violência em seus cadernos de Polícia. Devido ao que as ORM e a RBA projetam como seu público, elas realizam escolhas editoriais que, como já dito, oscilam entre o supostamente objetivo e o chulo, com a violência sendo mais ou menos escancarada, mas sempre evidente.

Nessa relação entre a cultura do espetáculo e do medo, a morte nas narrativas jornalísticas desses diários é apresentada como parte de um cotidiano social organizado ao modo de um terreno maniqueísta. Nele, de um lado, há o bem e o bom, representados por indivíduos nomeados como o "trabalhador", o "inocente", o "empresário", o "morador", que são vítimas ou de uma fatalidade, - eventualidade em que a morte é uma consequência imprevisível - ou de uma violência incontrolável presente nos espaços da cidade ou do interior do estado; todos pacientes de uma violência tanto mais brutal quanto mais inesperada para eles. Do outro, há também o mal e o mau, cujas figuras são dos indivíduos que estão em relações perigosas com o tráfico de entorpecentes ou com o crime, que representam um risco à sociedade, pela sua localização marginal e desalinhada de um ideal produtivo, que são vítimas das próprias escolhas pela violência e pelas relações regidas por ela; todos são apresentados como os agentes da violência cujas mortes são consequências de seu "caminho", do seu desvio. Desta forma, essas mortes são esperadas, e mais do que isso, são naturalizadas.

Esse tipo de construção é possível pelos aspectos da própria narrativa jornalística, que para Motta (2013) constitui uma modalidade de ação simbólica com a finalidade de organizar a experiência de um contexto, a partir de elementos que se tornam presentes na sua constituição, por meio de estratégias relativas a um pano de fundo social e simbólico. Por isso, as narrativas não são só relatos representativos: dialogam com compósitos de referências no âmbito das "metanarrativas", cujos significados simbólicos profundos se ligam a uma ordem, moral ou às crenças compartilhadas, justamente o âmbito das representações. É por essas características que essa ação da mídia elabora e reitera imagens, narrando a morte, representando-a desse modo dualista, como a morte inesperada dos bons e a morte naturalizada dos maus. À guisa 
de exemplo, observemos os seguintes trechos retirados da mesma edição de um dos jornais:

Dupla mata feirante a tiros; vítima saía de casa para trabalhar. Natalino foi atingido na cabeça, em uma das pernas e nas costas. Após os disparos os dois bandidos fugiram do local sem levar nada da vítima. A esposa e a filha caçula do feirante, que estavam na casa, ficaram, desesperadas e pediram ajuda aos vizinhos. [A vítima] morava na rua há mais de 10 anos e era um homem trabalhador [...] 'Esse vizinho era uma pessoa alegre, gentil e um trabalhador. E de repente vem uma pessoa e tira a vida dele, não dá para acreditar', disse o vizinho. (Amazônia, 21 maio 2013, p. 42).

"Thoki" morre atingido por quatro balaços. O envolvimento com drogas pode ter sido o motivo do assassinato de um rapaz identificado apenas pelo prenome Alexandre. Ele foi morto com quatro tiros ontem, no bairro da Marambaia. [...] Segundo o sargento Vinente, testemunhas disseram que já tinham visto a vítima pela área, mas ninguém soube informar onde ele morava. 'Nos informaram que ele era usuário de drogas e possivelmente foi isso que motivou o crime' disse. (Amazônia, 21 maio 2013, p. 47).

Há decerto uma dimensão das representações, à medida que o jornal evidencia, no primeiro texto, que há uma morte com um caráter incógnito, pois é de alguém que é "pessoa alegre, gentil e um trabalhador", que, portanto, não merecia morrer. Ao contrário do segundo texto, em que a morte se mostra como resultado inevitável da ordem das motivações bem definidas, porque a vítima era supostamente usuário de drogas, caracterizando o desvio. Olhar esses jornais permite-nos a observação de que essa leitura maniqueísta da realidade é o que dá sustento à reiteração das representações sobre a morte e o desvio nesses impressos. De modo que procuramos entender as referências dos acontecimentos e do social que são acionados a partir das representações sobre a fatalidade e de naturalidade nas narrativas sobre a morte e o morrer nos cadernos de polícia.

Compreendemos a ação das mídias jornalísticas nesse circuito simbólico, de captação dessas representações que circulam no tecido social, integrado às rotinas narrativas, partícipes de uma construção social da violência, do medo e do desvio como fenômeno de dimensões simbólicas e subjetivas. A mídia 
não constrói de modo totalizante os fenômenos, mas os tematiza de determinados modos, condicionando a percepção social do fenômeno. A mídia, como pontuado anteriormente, é um dos dispositivos que participam dessa construção social, à medida que o sentido da nossa realidade e da experiência passa também por ela, em uma relação em que as vivências diretas, cotidianas e imediatas com a violência são menos recorrentes e disseminadas do que as experiências objetivadas nas representações (Michaud, 2001).

\section{Modus narrandi MIDIÁTICO E OS PROCESSOS REPRESENTACIONAIS}

À medida que compreendemos o jornalismo na configuração do mundo representacional a partir do fenômeno da violência, podemos pensar como as representações são inscritas nessas narrativas jornalísticas, a fim de podermos mapear o quadro a que nos propomos, sobre morte e desvio. As narrativas jornalísticas, como infere Motta (2013), são atividades socioculturais de constituição da realidade, operando pela recriação de um sentido público dos acontecimentos. Essas narrativas constituem o mundo à medida que reafirmam e reiteram o canônico, legitimam e estabilizam o desviante nos acontecimentos; elas "constituem experiências essenciais para indivíduos e sociedades porque tornam natural o mundo social, tal como ele se apresenta" (Motta, 2013, pp. 54-55, grifo do autor). $\mathrm{O}$ autor defende que as narrativas jornalísticas devem ser pensadas também como representações sociais, que falam sobre o mundo material e social, porque "instituímos representativamente o mundo e nele performativamente atuamos" (2013, p. 32).

As representações nas narrativas são também o que está em circulação no ambiente representacional, não prescindindo, portanto, dos processos expressos na função social delas, quais sejam a ancoragem e a objetivação. Nas narrativas dos impressos da Amazônia Paraense, as representações da morte, mesmo que sejam parte de uma atividade de narrar o crime ou eventos que resultam em óbito, evidenciam questões que se inserem em um âmbito social das concepções partilhadas pela sociedade e vividas pela mediação que a mídia enseja.

Para Jovchelovitch (2000), na comunicação em que as representações se inserem, é preciso pensar como elas se desenvolvem a partir de um objeto social e alimentam a sua constituição. Esse aspecto nos permite pensar a produção das representações sobre a violência, à medida que as representações se 
desenvolvem sobre o fenômeno da violência e, a partir da sua difusão, passam a integrar não só as relações com tal fenômeno, mas a compor seus aspectos subjetivos. Por isso mesmo, pensá-lo a partir do local tem a ver com pensar as diferenças, o oculto e compreender complexidade de uma teia simbólica (Jovchelovitch, 2000).

Assim, pensamos a narrativa, nesse processo de organização simbólica da realidade da violência e na definição dos indivíduos como bons e maus, a partir dos dois processos acima citados, conforme os expõe Moscovici (2011): a ancoragem e a objetivação, entendidos como processos de classificação e nomeação, que tornam fenômenos, pessoas e acontecimentos não familiares em familiares, reconhecíveis, fazendo-os existir em um mundo conceitual e consensual, no qual são transformados em uma realidade vivível, tangível, concreta, em que às imagens são conferidas significações, de modo que o difuso e profuso são organizados.

A ancoragem ocorre, segundo o autor, dentro de alguns parâmetros, quais sejam o da categorização, transformando aquilo que potencialmente nos desestabiliza em um sistema de categorias, que comparamos com paradigmas de categorias já existentes, cuja relação julgamos adequadas, de modo que esses objetos ou pessoas adquirem, no nível representacional, as características dessa categoria, sendo "re-ajustado" a ela. Assim, o processo da ancoragem insere o problema da classificação e da nomeação, que estabilizam o estranho, o não familiar, porque o categorizam por meio de um nome e por meio da sua inserção em sistema de classificações, de modo que "nós podemos representar o não usual em nosso mundo familiar, reproduzi-lo como uma réplica de um modelo familiar" (Moscovici, 2011, p. 62).

A classificação e a criação de classes instauram um procedimento de definir comportamentos e práticas que são ou não permitidos em relação a essa e as demais classes. Isso se dá por meio do "protótipo", modelo representacional para comunicar o paradigma a que foi ancorado. Pessoas ou acontecimentos são comparados a um protótipo, socialmente aceito, na representação de uma classe, por meio da seleção das características mais significativas desse protótipo, que passam a se aplicar a toda classe de objetos sociais membros dessa categoria, sobretudo, a partir de uma dimensão normativa.

Quanto à nomeação, implica a inserção do objeto social em um complexo de palavras que conferem identidade a ele, sobretudo, porque "o que não pode ser nomeado não se pode tornar uma imagem comunicável ou ser facilmente 
ligado a outras imagens" (Moscovici, 2011, p. 66). Procede-se no estabelecimento da relação entre palavras e coisas, que torna possível representar a realidade, fazer com que determinadas características adiram à pessoa ou coisa e permitam a sua descrição, diferenciando-as e distinguindo-as de outras, tornando-as parte de convenções partilhadas, compondo e realimentando uma espécie de vocabulário ancorado ao da vida cotidiana. "Seu principal objetivo é facilitar a interpretação de características, a compreensão de intenções e motivos subjacentes às ações das pessoas, na realidade, formar opiniões (Moscovici, 2011, p. 70).

Quanto à objetivação, refere-se ao processo de transformação desses elementos ancorados em uma realidade, em que aquilo que pode ser percebido como incomum pode passar a integrar a experiência do vivido; o não familiar se torna realidade, é representado como um nível de realidade, consistindo, pois, na materialização de abstrações, em "transformar uma representação na realidade da representação; transformar a palavra que substitui a coisa, na coisa que substitui a palavra" (Moscovici, 2011, p. 71). Objetivar é reproduzir conceitos em imagens representacionais, preenchendo vazios com sentidos concretos que sejam equivalentes aos objetos a que as palavras e referem. Isso se manifesta no que o autor chama de "núcleo figurativo", um complexo dessas imagens que gera um complexo de ideias, um paradigma de sentidos, encapsulado em imagens, clichês e fórmulas criados pelas palavras que a ele se referem.

É esse complexo que se constitui a realidade, dando forma e sentido às personalidades dos sujeitos e às suas ações. Por meio dessas imagens, o conceito se descola do objeto originário, indo do abstrato para a existência independente, permitindo tensionar imagem e realidade, no âmbito da aparência. Isso instaura o problema da percepção, pois as imagens integram uma dimensão real, não só do pensamento, em que "a defasagem entre a representação e o que ela representa é preenchida, as peculiaridades da réplica do conceito tornam-se peculiaridades dos fenômenos, ou do ambiente ao qual se referem, tornam-se a referência real do conceito" (Moscovici, 2011, p. 74). Isso demarca a passagem das imagens de um ambiente meramente conceitual, entre palavras e objetos, para um âmbito de existência como os próprios objetos que elas significam.

Nesse processo, determinados procedimentos e instrumentos são empregados para transformar as representações em realidade, por meio de recursos 
como, por exemplo, a linguagem. Pensamos, assim, as narrativas jornalísticas sobre morte por violência urbana implicadas nesses processos de ancoragem e objetivação, nos termos já descritos: da demarcação da existência dos bons e dos maus. Essa reflexão sobre a representação da morte violenta pensa como ela aparece em um processo de fornecimento de experiência e conhecimento sobre a realidade social, a partir da tematização e narrativização especificas, que analisamos a seguir.

\section{A MORTE Violenta NA Mídia PARAEnSE}

Tópicos como o aumento da violência e da sensação de insegurança são projetados nas narrativas midiáticas e evidenciados nesses impressos a partir da exposição reiterada da morte. As representações nas narrativas englobam definições da realidade e dos sujeitos sociais, de modo que vemos a reapresentação do mal e dos maus, representados por "bandidos", usuários de drogas, entre outros; e do bem e dos bons, representados por trabalhadores, estudantes, donas de casa, etc. Uma vez constituídas, as narrativas das mídias paraenses reapresentam, rearranjam e reconstroem as representações que cercam essas mortes por violência urbana no Pará, pondo-as novamente em circulação no ambiente sociossimbólico do qual emergem, integrando a elas referências e valores tanto midiáticos quanto da vida cotidiana dos contextos em que a violência é fenômeno social.

Ao falar de morte - que aparece de formas variadas de acordo com o contexto do meio e da cobertura - a mídia evidencia sentidos que se aproximam de uma profusão de mortos célebres que desfilam em um cortejo, do qual os mortos banais estão apartados (Mouillaud, 2002); de mortes naturais de personagens que, sendo célebres, são igualmente queridos, contrastando a imagem de um morto anônimo por uma causa externa violenta ou ainda do registro de um morto que ao ser vítima de morte violenta é apresentado como inimigo da cena pública (Matheus, 2011). Todas essas mortes, porém, ao se projetarem em narrativas midiáticas, inscrevem-se no cotidiano, na experiência, pela sua dimensão representacional.

Assim, os processos simbólicos que participam da construção social das representações nos ajudam a pensar o que está presente nas narrativas sobre violência e se espraia a partir delas, os conhecimentos expressos pelos fenômenos enquadrados pela narrativa midiática. Pensamos isso dentro do quadro 
maniqueísta já destacado, em que a morte é preenchida de significado, os indivíduos são representados a partir de determinadas características e ações, classificados, nomeados, de modo que as mortes são objetivadas a partir de duas grandes categorias: a fatalidade da morte inesperada dos bons e a normalidade da morte naturalizada dos maus.

\section{A Fatalidade da MORTE Violenta}

A categorização que se opera nos termos da ancoragem faz com que essas mortes ostentem a marca do comum, na virtualidade do cotidiano, na virtualidade do risco da cidade. As causalidades apresentadas são da ordem do acidente de trânsito ou da brutalidade de assaltantes e criminosos. Essa morte na narrativa se distingue tanto pelas circunstâncias quanto pelos indivíduos a quem afetou. Procede-se à sua nomeação, identificando "trabalhadores", "donas de casa", pessoas "queridas pela comunidade", personagens e vítimas dessa violência. Há também a ênfase, maior ou menor, na imagem do morto como alguém que é atingido por um acontecimento fora do controle, acidental ou brutal, do qual ele não faz parte, mas pelos quais são afetados. É em razão dessa ancoragem que se encontra uma maior presença na narrativa de nuanças dramáticas, ao mesmo tempo indicando a fatalidade dos eventos e a perplexidade diante deles.

No caso dos acidentes e da ancoragem da morte, são narrativizados como a perda do controle, evidenciando uma falha, regida por uma casualidade. Elas reforçam a dimensão de uma violência virtual que pode atingir a todos, sem os atingir por razões especificas, a partir de uma ordem de causalidades morais ou das consequências de engajamento em um risco. É nesse sentido que podemos falar das seguintes narrativas.

Motociclista morre em batida. Luís Fernando Alves Pinheiro, de 53 anos, morreu após a moto que pilotava se chocar contra uma caminhonete na noite de ontem, por volta de 19 horas, na avenida Magalhães Barata, às proximidades da avenida Alcindo Cacela, São Brás. Uma ambulância do Corpo de Bombeiros foi acionada, mas não houve tempo de socorrer a vítima. "Eu estava em um táxi pela Magalhães Barata e o motorista do carro deixou ele [piloto da moto] passar porque ele já vinha correndo muito. Aí um pouco mais à frente, entre a 14 de Março e a Alcindo Cacela, ocorreu o acidente. A senhora do carro não teve 
culpa", afirmou Magna [testemunha]. (Amazônia, 22 mai. 2013, p. 41).

Dona de casa morre atropelada próximo à BR-316. A dona de casa Raimunda Ângela, 49 anos, mãe de cinco filhos, morreu atropelada por um veículo de passeio quando tentava atravessar a rodovia BR-316, no sentido São Brás/Entroncamento, distante apenas cerca de 100 metros do pórtico de Belém, onde existe uma passarela para a travessia de pedestres. [...] Ela estava na companhia do marido Jurandir Alves de Souza, de 48 anos. "[...] Acho que a culpa foi nossa, não sei, ficamos tão confusos. Deveríamos ter atravessado na passarela. Não sei nem o que dizer e pensar, mas já sinto a falta dela, pois vivíamos juntos há seis anos", disse, emocionado. (O Liberal, 16 mar. 2012, p. 1)

Motoqueiro bate em caminhão e morre na BR-316. Na madrugada de ontem, um acidente entre uma motocicleta Honda Broz e um caminhão caçamba, no KM 3 da rodovia BR-316, em Marituba, deixou uma vítima fatal. O motociclista Walber Luis Borges da Silva, 24 anos, teve morte instantânea ao colidir com a traseira de um caminhão carregado de areia. A força da colisão foi tanta que pedaços de massa encefálica da vítima ficaram espalhados no para-choque da caçamba. (Diário do Pará, 14 mar. 2014, p. 7)

Uma morte por acidente do qual não se teve culpa, no primeiro excerto; a morte de uma mãe, acompanhada pelo marido, que se culpa e fala sobre a morte da esposa, no segundo; uma "vítima fatal" cuja vida se perdeu em um acidente brusco e brutal. Essas narrativas todas fazem mais do que narrar sobre o acidente, elas alimentam no saber cotidiano a ideia do perigo urbano. Organizam essas ocorrências difusas por meio da nomeação de cada ocorrência como um acidente, que permite a construção narrativa da morte como abrupta e súbita ruptura, em que o humano é mais ou menos um coadjuvante, ou seja, uma ruptura que se sobrepõe aos envolvidos, na ideia de que houve exatamente a falha na situação, causada por um acaso ou uma imprudência.

Um itinerário narrativo cujos elementos são dispostos e arranjados com vistas a destacar um modo de morrer específico, moderno e dessacralizado. Esses elementos são responsáveis pela ancoragem do acontecimento a essa definição do fatal, em que "não houve tempo de socorrer a vítima"; " "acho que a culpa foi nossa [...] já sinto a falta dela"” e mesmo "deixou uma vítima 
fatal" de cada um dos casos, respectivamente. A nomeação do acidente se constitui como conferência de identidade a ele, permitindo a organização desses eventos difusos, por meio da classificação das referências de um tempo e um espaço, dos indivíduos cuja morte constitui o objeto narrativo, das relações dos indivíduos com as mortes. Essa classificação tem o papel de restringir e alimentar a representação da fatalidade, do morrer como elemento de um cotidiano de risco, passível de atingir os indivíduos indistintamente.

Ela projeta a representação de um morrer definido com causalidade identificada, mas em uma casualidade de fenômenos, ainda que nos registros de segurança pública, as mortes decorrentes por acidente de trânsito sejam parte das estatísticas de crimes contra a pessoa e homicídios. Essa representação não deixa de evidenciar que esse evento se projeta como uma pequena tragédia privada, causada por uma situação não motivada, - mas muito mais como uma violência não motivada - podendo assumir um caráter violento ao afetar a vítima e seu entorno. É nessa descrição que se operam a classificação e a nomeação.

O outro lado dessas representações, ainda com a classificação do fatal, é em relação às mortes que resultam de um crime proposital, já da ordem da violência intencional, tida como motivada, porém imerecida, decorrente de homicídios, da força da violência que rege certos espaços e dos indivíduos que fazem parte deles: a periferia da cidade e os bandidos/criminosos que dela emergem, respectivamente. Rótulos como o de "trabalhador" são recorrentes em narrativas como essas, que nos fornecem alguns indícios do que seriam tais pessoas: alinhadas à ordem da produtividade e da ocupação, indicam pessoas potencialmente "boas", à medida que não se alinham com o tráfico ou com o crime predominante, em oposição àquelas de que são vítimas. Neste caso, a representação se complexifica, pela ancoragem de outros elementos além das circunstâncias, englobando também estereótipos de comportamentos sociais em oposição.

Trabalhador é sepultado. Ontem de manhã, durante velório da vítima na casa da família, parentes e vizinhos lamentaram a morte trágica do autônomo, "Era um trabalhador que não se envolvia e confusão e era muito querido no bairro. Gostava de beber a cervejinha dele, mas não brigava com ninguém" disse José Mesquita, cunhado da vítima (Amazônia, 22 mai. 2013, p. 41). 
Polícia apura assassinato em Icoaraci. Até ontem a Polícia Civil, em Icoaraci, não tinha pistas dos homens que, armados, executaram a bala o funcionário público Robson Clóvis Monteiro Campos. O fato se registrou anteontem quando a vítima foi atingida com três tiros. Foi um tiro no queixo e dois na cabeça. [...] O delegado descartou a possibilidade de que o crime tenha ido motivado por um acerto de contas, já que as informações disponíveis indicam que Robson era um homem trabalhador. (O Liberal, 30 abr. 2012, p. 6)

Professor é assassinado com quatro tiros. O professor Raimundo Lucier Marques Leal Junior, 59 anos, foi morto a tiros dentro de seu veículo, no início da tarde de sábado, na avenida Duque de Caxias, entre as travessas Eneias Pinheiro e Pirajás, bairro do Marco. Segundo informações da polícia, o homem que efetuou os disparos estava aguardando a vítima sair de uma oficina mecânica, próximo do local. [...] Os familiares da vítima ficaram desolados com a situação e receberam apoio de amigos e colegas do professor que foram ao local do homicídio. Bastante emocionados, os parentes de Raimundo Lucier preferiram não conversar com a imprensa. (Diário do Pará, 06 ago. 2012, p. 4)

Morte lamentada por família, parentes e vizinhos; morte violenta por arma de fogo, mas de um homem trabalhador; morte de um professor, que causa desolação na família. Nos casos acima, a aparição de designativos em "lamentaram a morte trágica do autônomo", "era um homem trabalhador" e "familiares da vítima ficaram desolados com a situação e receberam apoio de amigos e colegas do professor", serve para ancoragem dos papéis sociais das vítimas, funciona como elemento que as distingue, à medida que são pessoas que se alinham com bem, são o bom indivíduo, cuja presença na sociedade é o avesso da violência que os afeta, cuja existência social não é marcada por uma marginalização extrema, pois, mesmo nos nichos periféricos, os ideiais produtivos e distintivos do trabalhador e do indivíduo com uma profissão o afastam de ser parte integrante da sociabilidade violenta.

A fatalidade aqui é evidenciada pelo encontro do indivíduo que nada tem a ver com a violência, mesmo que ele esteja no espaço que é definido por uma ordem social marginal, "naturalmente" a periferia violenta, em que sua morte é causada por essa sociabilidade e potenciais gestões de conflito violentas, externas a ele. Há um movimento simbólico de personificação dessa violência 
que vitimiza as pessoas das regiões periféricas. É tão somente a morte violenta pelas mãos de "bandidos", assaltantes. Trata-se de um perigo que, na narrativa, é bem definido.

Do ponto de vista de uma construção narrativa sensacional, que dialoga com as representações, isso se exprime na apresentação dos elementos de lamento, da dor, representada pela própria vítima e a realidade que ela evoca, pois na medida em que ela pode ser um ente individual, pode também, simbolicamente, ser um conjunto de outros entes, potenciais vítimas ou afetados pelo fato; a experiência da dor colaborando com o medo. Deste modo, a leitura que os impressos em análise nos fornecem é que realidade cotidiana de quem está nas regiões periféricas é cercada de uma potencialidade do morrer, uma fatalidade a que estão mais ou menos suscetíveis os moradores dessas regiões.

Isso se insere em um quadro maior de classificação, que implica na objetivação das representações. Do ponto de vista que as mortes por fatalidade constituem uma totalidade de imagens, arranjadas em similitude, fazendo-as familiares, de modo a se reconhecer o ambiente da cidade como o ambiente do perigo, tal como na cidade do medo. A sua constituição como núcleo figurativo interfere no problema da percepção da violência, pela objetivação das representações que afirmam o quão violenta a sociedade se tornou. Passamos a ver nessas ocorrências, espalhadas no tecido social, a violência que pode potencialmente nos atingir diariamente, com a qual convivemos e que tememos. Em última instância, podemos dizer, essas narrativas, como objetos acessíveis socialmente, instauram uma ordem simbólica, em relação às mortes inesperadas dos bons, que define aquilo que é apropriado, os tipos sociais não desviantes, ancorados a uma categoria representacional do bem na sociedade que tem medo de si.

\section{A NORMALIDADE NA MORTE VIOLENTA}

Esse quadro representativo não se confunde com o anterior, pois os elementos ancorados buscam mostrar que, ao contrário de inscrever a morte em uma situação indesejada, que enseja lamento e perda, ruptura daquilo que se espera da vida dos indivíduos, a morte aqui é sempre de pessoas que encarnam a violência, que fazem parte de uma rede de relações marcadas por reciprocidade negativa, com um "fim" esperado. Falam-se, então, de mortes 
normalizadas, naturalizadas. Os casos de desentendimentos entre "bandidos", de dívidas com o tráfico, de acertos de conta são representados a partir deste viés. É a rotinização da realidade de um outro que é violento, causador da violência e eliminado por ela mesma. É o caso mais típico das narrativas midiáticas. É a construção de uma alteridade perigosa. Elas apresentam uma grande quantidade de indivíduos, de assaltantes a usuários de drogas, que representam potencialmente o perigo para aqueles em relação ao qual ele é o outro. Tomemos alguns exemplos.

Viciado tomba a tiro. Mauricio Ferreira Farias, 21 anos, foi morto na madrugada de ontem na passagem Nossa Senhora das Graças, na Pratinha II, logo após sair de uma festa. Ele era usuário de drogas e já havia sido preso pelo crime de roubo, informação que foi confirmada pela mãe dele, Antônia Ferreira, que esteve no local do crime. [...] A polícia não descarta a hipótese de acerto de contas na investigação do homicídio. A equipe da Divisão de Homicídios esteve no local do crime para levantar informações sobre o homicídio (Amazônia, 18 jun. 2013, p. 45).

Bandido tomba em acerto. Luan Santos Moreira, de 23 anos, foi morto com três tiros, ontem à noite, no bairro da Condor, em Belém. Segundo a polícia, a vítima tinha envolvimento com crimes e a principal suspeita é que o assassinato tenha sido um acerto de contas. [...] "No momento que ele desceu da van e entrou aqui na passagem, os motoqueiros o perseguiram alguns metros e um deles efetuou os disparos contra a vítima", complementou o PM. "Luan do Guamá", como era conhecido, morreu na hora. Segundo denúncias recebidas pela polícia, o rapaz era considerado perigoso, já que tinha envolvimento com assaltos e homicídio. "Temos a informação de que ele já foi preso por homicídio. Em 2011, ele matou o próprio comparsa. Ele era perigoso, muito conhecido no Guamá pela prática de crimes", afirmou o policial. (Amazônia, 14 set. 2013, p. 47)

Usuário de drogas inadimplente é executado por traficantes. Um homem foi assassinado, sábado à noite, na Cabanagem, em Belém. André dos Santos Corrêa, 29 anos, estava caminhado na passagem Bom Jesus, do Conjunto Panorama XXI, quando um homem a pé se aproximou e efetuou um disparo que atingiu a nuca da vítima. Segundo a polícia, o 
motivo da execução foi acerto de contas por dívida com traficantes do bairro. André era usuário de drogas. (O Liberal, 20 ago. 2012, p. 5)

Técnico em refrigeração assassinado porque devia $\mathrm{R} \$ 50,00$ ao criminoso. Um homem foi assassinado quando estava às proximidades da residência cia onde morava, na Marambaia. [...] A informação que chegou à polícia é que a vítima tinha passado a madrugada em um bar na companhia do assassino. E o crime teria sido motivado por dívidas de droga. [...] "Quando ele estava a caminho de casa, foi atacado pelo criminoso. Eles brigaram por uma dívida de $\mathrm{R} \$ 50,00$ gasto em droga", disse o cabo. O assassino puxou a faca e golpeou a vítima 28 vezes José ficou ferido até na cabeça. (O Liberal, 03 set. 2012, p. 1)

Sevilha: cinco tiros ceifaram a vida de Bruno. Um homicídio com sinais evidente (sic) de execução, Bruno Péricles de França Alves, 21, foi executado friamente em um beco do Jardim Sevilha, às margens da Augusto Montenegro, conhecido como "beco do me rouba"por dois homens em uma motocicleta que dispararam uma rajada de tiros contra a vítima. [...] Uma informação repassada ao DIÁRIO por uma testemunha dá conta que Bruno Péricles teria cometido um delito no bairro dos 40 Horas, em Ananindeua, e estaria com sentença de morte decretada pelos possíveis vingadores de sua vítima. (Diário do Pará, 23 abr. 2012, p. 3)

Assaltante é liquidado com oito tiros. Na noite da última quarta-feira (10), por volta das 21h30, Cherllesso Santos da Silva, 25, Foi morto com pelo menos oito tiros, na rua Getúlio Vargas, bairro Água Boa, na ilha de Caratateua, mais conhecida como Outeiro, que é distrito de Belém. De acordo com informações da polícia, a vítima pode ter sido morta por acerto de contas entre assaltantes. [...] Conforme apurações da polícia, Cherllesso além de ter sido envolvido em assaltos, também era viciado em entorpecentes. (Diário do Pará, 12 out. 2012, p. 3)

O usuário de drogas que já havia sido preso, morto após sair de uma festa; a vítima com envolvimento em crimes, que é morta por acerto de contas com os traficantes de drogas, mas uma vítima que já matou; morte por arma de fogo por mais um suposto acerto de contas; morte por uma briga causada pelo dinheiro gasto em entorpecentes; uma morte violenta de um ladrão, expressa em uma "sentença de morte", em um lugar marcadamente perigoso; e mais 
uma morte cuja vítima é "liquidada" pela agressividade voraz dos executores, também assaltantes nas tramas da violência urbana.

Com exemplos dos três impressos, percebemos recorrências nas narrativas, no modo de apresentar seus elementos e encadeá-los simbolicamente. Uma rotina da narração da violência que projeta representações da morte dos indivíduos à margem da ordem social. Os elementos de ancoragem da situação são esquemáticos e tautológicos. Há a repetição da ideia da suspeita de execução, do designativo "acerto de contas", de uma espécie de histórico de envolvimento com a criminalidade, como elementos justificadores da morte nesse contexto periférico e do morrer proveniente dessa gestão da violência, realizada pelos próprios indivíduos violentos, com vistas a regular as relações nesses espaços.

Trata-se da representação do bandido armado ou os congêneres que com ele compactuam, encarnando uma personificação do mal. São o mal no sentido de serem um signo da própria violência que afeta a sociedade, para a qual representam um risco iminente. É na construção narrativa que nos deparamos com a representação da morte como castigo pelas relações em que a vítima, voluntária e conscientemente, teria se inserido. Uma consequência de um desvio social, legal e moral, que, ainda que não confirmado em alguns casos, apenas atestado por depoimentos, reforça a noção de uma violência e uma brutalidade com finalidades e causalidades bem demarcadas, em todas as possíveis facetas naturalizada.

Essa naturalização e ideia da normalidade da morte dos maus se operam à medida que esses indivíduos e suas mortes passam a integrar um paradigma representacional, por meio da objetivação, que faz com que o núcleo figurativo das imagens seja percebido como o fenômeno ele mesmo. Desse modo, nas narrativas se encontram os elementos que compõem todo o quadro da morte naturalizada: explicações de que as mortes acontecem por acertos de contas, de dívidas com o tráfico, com as quais estabelece uma relação de causalidade, que delimita, reduz e facilita qualquer interpretação sobre aquele evento. Não obstante, essas representações passam a integrar um contexto típico, o familiar, o próximo, a realidade dos espaços urbanos da vida comum, no qual a ideia da periferia da cidade marcada por violências espetaculares e explosivas é a representação predominante, espalhando o medo pelos outros espaços.

Isso insere, da ancoragem à objetivação, o problema da identificação e da definição dos desviantes da Amazônia urbana. Se, nas representações da fa- 
talidade, os indivíduos a quem a violência urbana atinge, são os tipos sociais apropriados e alinhados, os indivíduos nas representações da morte normalizada são os tipos desviantes, que representam desalinho, perigo, desequilíbrios à ordem. São os agentes da violência objetivados pelas representações. Desse modo, a mídia reitera as imagens já circulantes de que determinados indivíduos têm uma morte definida e, em certa medida, ao realizar o movimento simbólico de os afastar do espaço ao qual pertencem e no qual não merecem viver, joga-os no meio de um espetáculo em que a morte deles é impressa nas páginas dos jornais com todas as marcas da violência e da sua suposta desumanidade, reforçando as formas de perceber a realidade, nas quais a morte para eles é a norma, cujo cumprimento é esperado e quase inevitável.

\section{CONSIDERAÇÕES FINAIS}

No contexto da Amazônia urbana, assim como de outras regiões do Brasil, as narrativas jornalísticas sobre violência são relatos nos quais se inscrevem representações, que as fazem circular e que constituem, em grande medida, os conhecimentos desse objeto social. Elas estabelecem parâmetros interpretativos a partir dos quais perspectivamos a cidade, seus indivíduos, seus perigos e o medo em relação a eles. Elas se inserem em uma dimensão de fornecimento de conhecimento social a respeito do fenômeno, porque os integram ao familiar, à vivência, ao perceptível, ainda que não se tenha experiência direta e imediata com a violência urbana. Elas fazem com que esse fenômeno da vida social brasileira circule, de modo dinâmico, aumentando a extensão e o potencial das representações sociais. Nessa circularidade, as representações dos fenômenos são ainda mais estabilizadas e consolidadas, pela formação de núcleo figurativos e paradigmas representacionais cada vez mais amalgamados, organizando os eventos difusos que são percebidos como a manifestação dessa problemática social.

Especificamente, as mortes por homicídios ou acidentes constituem o alimento principal dessas narrativas, ao mesmo tempo que constituem a face mais visível e visibilizada dessa violência urbana. À dimensão do espetáculo deve-se somar a dimensão constitutiva de um ambiente sociossimbólico, que, marcado pelo medo do perigo, do outro, do risco, condiciona os nossos modos de habitar o mundo, de percebermos a nós mesmos, de percebemos os outros. A comunicação midiática é um partícipe relevante na manutenção 
da sociedade pensante. No contexto que analisamos, as narrativas jornalísticas operam um processo de construção social das representações da violência: ancorando e objetivando tanto a morte quanto o desvio. Apontando aqueles que do crime estão apartados, os bons, que, no entanto, podem ser potenciais vítimas; assim como aqueles que são dele parte intrínseca, os maus, demarcando os espaços periféricos da cidade como o lugar de onde surgem e estabelecem relações com as dinâmicas dessa violência. Essas representações resultam na perspectivação de mortes que devem ser lamentadas, pelo seu aspecto de ruptura, e mortes que devem ser naturalizadas e reiteradas, pelo seu aspecto já convencional.

Desse modo, diante do ambiente sociossimbólico do medo da violência urbana, pensamos as narrativas como indissociáveis dele e um dos seus principais formadores. Opera-se um ciclo na constituição desse objeto social: à medida que as violências e o medos se generalizam, as narrativas falam deles para a sociedade; e à medida que falam neles, as narrativas generalizam os medos e a violência. O contexto é complexo, e o fenômeno social marca a vida urbana nas últimas décadas. A dimensão midiática da violência, constituída nas representações, aponta para o lugar central das mídias na objetivação, na construção dessa realidade, relativamente a esse fenômeno-problema. Do ponto de vista das repercussões sociossimbólicas que pontuamos neste trabalho, a narrativização de mortes por meio das representações maniqueístas, que categorizam o bem e o mal, encarnando-os em estereótipos, é o meio que instaura distorções de tematização, rotinização de deslocamentos e a negação do entendimento do fenômeno da violência como problemática que requer abordagens além do crime, da morte e do desvio.

\section{REFERÊNCIAS BIBLIOGRÁFICAS}

Baudrillard, J. (1991). Simulacros e simulação. Lisboa: Relógio d'Água.

Becker, H. (2008). Outsiders: estudos de sociologia do desvio. Rio de Janeiro: Jorge Zahar.

Brasil (2012). Seminário de segurança da Amazônia. Brasília: Secretaria de Assuntos Estratégicos da Presidência da República.

Castro, F. F. (2012). Comunicação, poder e democracia. Belém: Labor Edições. 
Cerqueira, D. R. (2014). Causas e consequências do crime no Brasil. Rio de Janeiro: BNDES.

Cohen, S. (2011). Folk devils and moral panics: the creation of the Mods and Rockers. London: Routledge.

Correia, J. C. (2009). Teoria e crítica do discurso noticioso: notas sobre jornalismo e representações sociais. Covilhã: Livros LabCom.

Costa, A. C. (2011). A violência e os modelos midiáticos de espetáculo. In M. Malcher et al. (Org.). Comunicação midiatizada na e da Amazônia (pp.179-204). Belém: Fadesp.

Ferreira Junior, S. \& Costa, A. C. (2016). Enquadramentos e representações sociais da violência urbana na imprensa da Amazônia paraense. Revista Estudos de Jornalismo, 5: 99-114.

Glassner, B. (2003). Cultura do medo. São Paulo: Francis.

Jodelet, D. (2001). Representações sociais: um domínio em expansão. In D. Jodelet (Org.). As representações sociais (pp.17-44). Rio de Janeiro: Ed. UERJ.

Jovchelovitch, S. (2000). Representações sociais e esfera pública: a construção simbólica dos espaços públicos no Brasil. Petrópolis: Vozes.

Jovchelovitch, S. (2008). Os contextos do saber: representações, comunidade e cultura. Petrópolis: Vozes.

Marcondes Filho, C. (2008). Para entender a comunicação: contatos antecipados com a nova teoria. São Paulo: Paulus.

Matheus, L. C. (2011). Narrativas do medo: o jornalismo de sensações além do sensacionalismo. Rio de Janeiro: Mauad.

Michaud, Y. (2001). A violência. São Paulo: Ática.

Moscovici, S. (2011). Representações sociais: investigações em psicologia social. Petrópolis: Vozes.

Motta, L. G. (2013). Análise crítica da narrativa. Brasília: Editora Universidade de Brasília.

Mouillaud, M. (2002). As grandes mortes na mídia. In M. Mouillaud \& S. D. Porto (Org.). O jornal: da forma ao sentido (pp.349-361). Brasília: Editora Universidade de Brasília. 
Porto, M. S. (2014). Violência e representações sociais. In R. S. Lima, J. L. Ratton \& R. G. Azevedo (Org.) Crime, polícia e justiça no Brasil (pp.60-70). São Paulo: Contexto.

Ramos, S. \& Paiva, A. (2007). Mídia e violência: tendências na cobertura de criminalidade e segurança no Brasil. Rio de Janeiro: IUPERJ.

Souza, M. L. (2008). Fobópole: o medo generalizado e a militarização da questão urbana. Rio de Janeiro: Bertrand Brasil.

Telles, V. S. (2010). A cidade nas fronteiras do legal e ilegal. Belo Horizonte: Argumentvm.

Tuchman, G. (2002). As notícias como uma realidade construída. In J. P. Esteves (Org.). Comunicação e sociedade: os efeitos sociais dos meios de comunicação de massa (pp.91-104). Lisboa: Livros Horizonte.

Veloso, M. S. F. (2014). Imprensa e contra-hegemonia: 20 anos de Jornal Pessoal (1987-2007). Belém: Paka-Tatu.

\section{Fontes}

Amazônia, n. 4762, 21 maio 2013.

Amazônia, n. 4763, 22 maio 2013.

Amazônia, n. 4790, 18 jun. 2013.

Amazônia, n. 4878, 19 set. 2013.

Diário do Pará, n. 10108, 14 mar. 2012.

Diário do Pará, n. 10148, 23 abr. 2012.

Diário do Pará, n. 10253, 06 ago. 2012.

Diário do Pará, n. 10320, 12 out. 2012.

O Liberal, n. 33508, 16 mar. 2012.

O Liberal, n. 33553, 30 abr. 2012.

O Liberal, n. 33665, 20 ago. 2012.

O Liberal, n. 33679, 03 set. 2012. 